\title{
Modeling and Simulation of power system using SMIB with GA based TCSC controller
}

\author{
${ }^{1}$ Jitendra Bikaneria, ${ }^{2}$ Surya Prakash Joshi
}

\begin{abstract}
Power system is always affected by transients that create oscillations \& voltage instability. Several techniques are invented to overcome instability problems \& improve power system performance. The most common used technique is power system stabilizer called PSS. The PSS has limit to damp the oscillations due to power grid network. So another device/stabilizer is required for system stability \& reliability. These requirements generate the vacancy for FACTS \& FACTS devices like SSC, IPFC, UPFC, SVC \& STATCOM. In this paper we used TCSC as controller for stability of power system \& tuning of TCSC is done by the genetic algorithms. The effect of TCSC controller is demonstrated by using SMIB.

General Terms: In recent years, significant development has been come out in power system stability improvement, particularly FACTS transmissions \& FACTS devices. The power systems are connected as large system through EHV lines. The methods of grid management \& operation is also upgraded with advancement in the socioeconomics. Power system strongly demands security, reliability \& stability, efficient \& flexible operations. So it attract new researchers to developing new regulation techniques with enhance controller.
\end{abstract}

Keywords: Power system, SMIB, FACTS, TCSC, GA.

\section{Introduction}

FACTs devices are used to increase power transfer capacity. These devices are able to control power sharply, increase stability with minimum losses, kept system in predetermined range of thermal limits \& also limit damping due to power system oscillations [1][2]. FACTS is a collection of controllers those can be applied as individuals or co-ordination with other controllers. Same basic technology is used for all types of FACTS devices. One of the FACTS device TCSC is used here to improve system stability during transient state due to oscillations in power system. The accurate tuning of TCSC controller is big challenge for researchers. A phase compensation method provides controlling at a point only. Genetic algorithm (GA) is used as robust optimization technique in various field of engineering so we used genetic algorithm (GA) to design TCSC controller [3].

\section{Power System}

The approx model of study power system is represented by SMIB with TCSC shown in fig.1. The power supplied by Synchronous machine to the infinity bus can be done through parallel transmission line with series TCSC device. The synchronous machine terminal voltage is shown by $\mathrm{V}_{t}$ while infinity bus voltage shown by $\mathrm{E}_{\mathrm{b}}$. Reactance of the transformer, transmission line per circuit \& equivalent Thevenin's impedance of receiving end of the system represented by $\mathrm{X}_{\mathrm{T}}, \mathrm{X}_{\mathrm{L}} \& \mathrm{X}_{\mathrm{TH}}$.

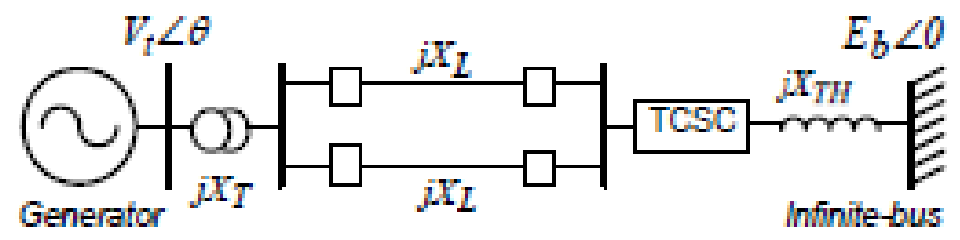

Fig.1: power system (SMIB) with TCSC.

\subsection{SMIB as Power System}

The synchronous machine is represented by a model of synchronous generator model1.1, i.e. with field circuit and one equivalent damper winding on $\mathrm{q}$ axis.

The machine equations are [4]:

The below equations and notations for the variables and parameters described are standard and defined in the nomenclature. 


$$
\begin{gathered}
\frac{\mathrm{d} \delta}{\mathrm{dt}}=\omega_{\mathrm{B}}\left(\mathrm{S}_{\mathrm{m}}-\mathrm{S}_{\mathrm{mo}}\right) \ldots \ldots(1) \\
\frac{\mathrm{dS}_{\mathrm{m}}}{\mathrm{dt}}=\frac{1}{2 \mathrm{H}}\left[-\mathrm{D}\left(\mathrm{S}_{\mathrm{m}}-\mathrm{S}_{\mathrm{mo}}\right)+\mathrm{T}_{\mathrm{m}}-\mathrm{T}_{\mathrm{e}}\right] \ldots . . \\
\frac{\mathrm{dE}_{\mathrm{q}}^{\prime}}{\mathrm{dt}}=\frac{1}{\mathrm{~T}_{\mathrm{do}}^{\prime}}\left[-\mathrm{E}_{\mathrm{q}}^{\prime}+\left(\mathrm{x}_{\mathrm{d}}-\mathrm{x}_{\mathrm{d}}^{\prime}\right) \mathrm{i}_{\mathrm{d}}+\mathrm{E}_{\mathrm{fd}}\right] \\
\frac{\mathrm{dE}_{\mathrm{d}}^{\prime}}{\mathrm{dt}}=\frac{1}{\mathrm{~T}_{\mathrm{qo}}^{\prime}}\left[-\mathrm{E}_{\mathrm{d}}^{\prime}+\left(\mathrm{x}_{\mathrm{q}}-\mathrm{x}_{\mathrm{q}}^{\prime}\right) \mathrm{i}_{\mathrm{q}}\right] \ldots .
\end{gathered}
$$

The electrical torque $T_{e}$ is expressed in terms of variables $E_{d}^{\prime}, E^{\prime}{ }_{q}, i_{d}$ and $i_{q}$ as following:

$$
T_{e}=\mathrm{E}_{\mathrm{d}}^{\prime} \mathrm{i}_{\mathrm{d}}+\mathrm{E}_{\mathrm{q}}^{\prime} \mathrm{i}_{\mathrm{q}}+\left(\mathrm{x}_{\mathrm{d}}^{\prime}-\mathrm{x}_{\mathrm{q}}^{\prime}\right) \mathrm{i}_{\mathrm{d}} \mathrm{i}_{\mathrm{q}}
$$

For a efficient network, the stator algebraic equations and the network equations are written as:

$$
\begin{gathered}
\mathrm{E}_{\mathrm{q}}^{\prime}+\mathrm{x}^{\prime}{ }_{\mathrm{d}} \mathrm{i}_{\mathrm{d}}=v_{\mathrm{q}} \cdots \cdots \\
\mathrm{E}_{\mathrm{d}}^{\prime}-\mathrm{x}_{\mathrm{q}}^{\prime} \mathrm{i}_{\mathrm{q}}=v_{\mathrm{d}} \\
v_{q}=-x_{e} i_{d}+E_{b} \cos \delta \\
v_{d}=x_{e} i_{q}-E_{b} \sin \delta
\end{gathered}
$$

Solving the above equations, the variables $i_{d}$ and $i_{q}$ can be obtained as:

$$
\begin{aligned}
& i_{d}=\frac{E_{b} \cos \delta-E_{q}^{\prime}}{x_{e}+x_{d}^{\prime}} \\
& i_{q}=\frac{E_{b} \sin \delta+E_{q}^{\prime}}{x_{e}+x_{q}^{\prime}}
\end{aligned}
$$

\subsection{TCSC Controller}

TCSC is a convenient \& common used FACTS device to control impedance of connected transmission line. TCSC mainly consist capacitor bank, inductor, bi-directional thyristor \& bypass capacitor. Basic diagram of TCSC shown in fig.2

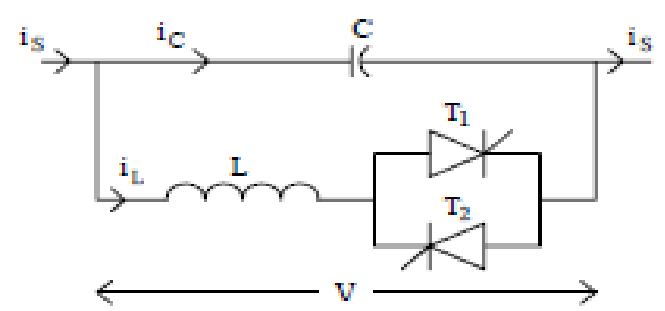

Fig.2: Basic diagram of TCSC controller 
Due to variation in thyristor firing angle $(\propto) \&$ conduction angle $(\sigma)$, this two features provides fast switch between corresponding reactance offered to the selected power system. We assume that the total current pass throughout the TCSC is sinusoidal. Steady state relations between conductance angle $(\propto)$ \& equivalent reactance of TCSC $\left(\mathrm{X}_{\mathrm{TCSC}}\right)[5]$ is

The block diagram of TCSC contains gain block, washout block \& two stage lead-leg block. The block diagram is shown below in fig. 3

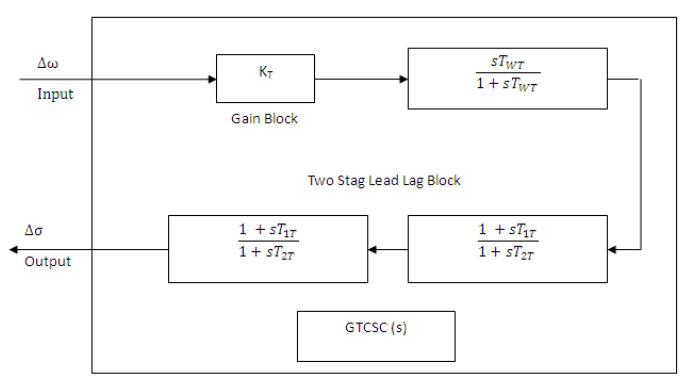

Fig.3: Block diagram of TCSC controller

TCSC input are given by deviation in rotor speed \& the output modulates $\Delta \sigma$ which control input signals for TCSC. The gain block is used to find damping level while phase compensator block used to compensate the lag between input \& output signal \& wash out block works as high pass filter to pass only high frequency signals only[5].

\subsection{Genetic Algorithm}

John Holland was introduced Genetic algorithms (GA) in the 1970s (Holland 1975) as a result of investigations into the possibility of computer programs undergoing evolution in the Darwinian sense. Genetic algorithms are based on mechanics of nature \& natural genetics. GA is used to find out optimal solution of number of equations \& iterations [6].

The two basic needs to apply GA:

1) Define objective function.

2) Genetic operator to obtain the required optimization.

Cycle operates in GA called generations.

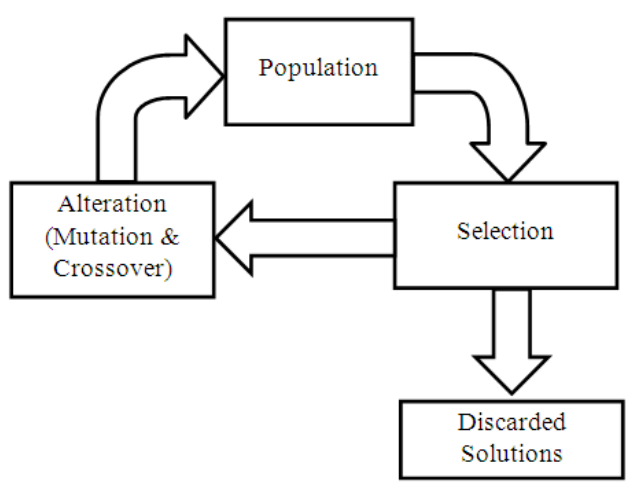

Fig.4: Genetic algorithm evolutionary cycle.

The GA evolutionary cycle starts with a randomly selected initial population. The changes to the population occur through the processes of selection based on fitness, and alteration using crossover and mutation. The application of selection and alteration leads to a population with a higher proportion of better solutions. The evolutionary cycle continues until an acceptable solution is found in the current generation of population, or some control parameter such as the number of generations is exceeded. 


\section{Simulation \& Results}

The power system model represented by SMIB as defined in equations above is simulated by using MATLAB. The oscillations are created by deviation in rotor speed of synchronous machine. The TCSC controller is introduced in system and performance is observed.

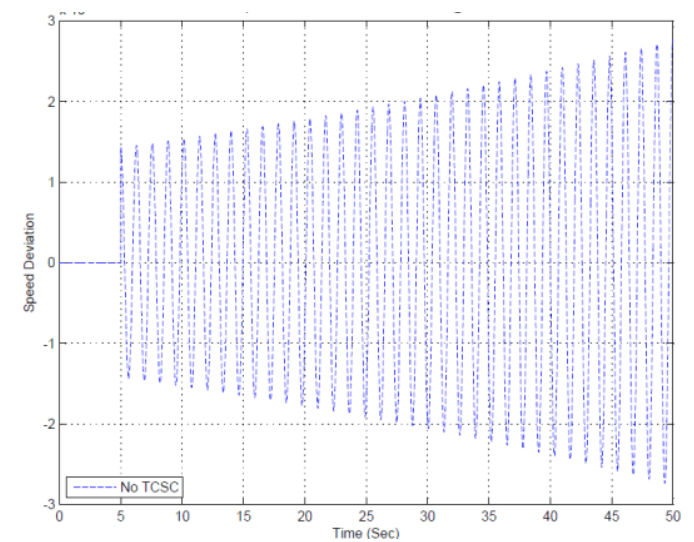

Figure1: Speed Deviation in SMIB with Fault without TCSC controller

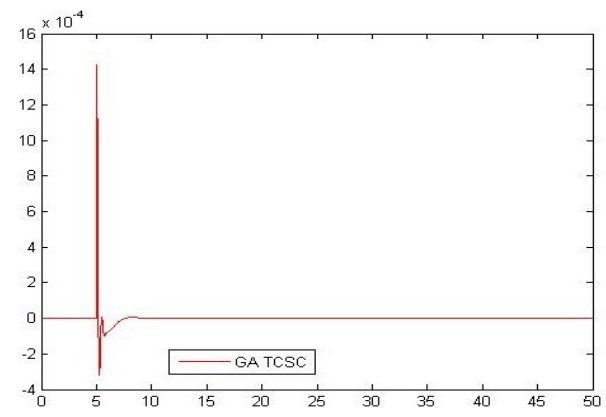

Figure2: Speed Deviation in SMIB with Fault with GA- TCSC

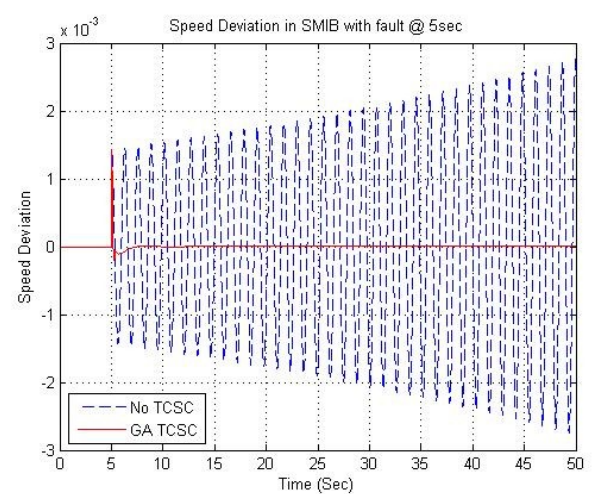

Figure3: Speed Deviation in SMIB with Fault without \& with GA- TCSC

\section{Conclusion:}

The behavior of power system without TCSC controller \& power system with TCSC controller are studied in this paper. Genetic algorithm is used for optimum tuning of TCSC controller. The simulation results shows genetically tuned TCSC controller improves stability performance of power system. Power system oscillations are damped out very effectively. This model shows that proposed model is suitable for carrying out power system stability studies when synchronous generator \& TCSC are main factors.

\section{Acknowledgments}

Our special thanks to Dr. Chandan Joshi. 


\section{References}

[1] N.G. Hingorani and L. Gyugyi, understanding FACTS: concept \& technologyof flexible AC transmission system, IEEE press, 2000 .

[2] H.F. Wang, F.J.Swift, FACTS-based stabilizer designed by the phase compensation method part I on single machine power system, advance in power system control, operation \& management, 1997. APSCOM-97, fourth international conferenceon 11-14 nov. 1997

[3] Richard C. dorf, Modern control system, Addison wesley publishing company, 1992.

[4] K.R. Padiyar, power system dynamicsstabilityand control, BS publications, $2^{\text {nd }}$ edition, Hederabad, India 2002.

[5] R. M. Mathur and R. K.Verma, thyristor-based FACTS controllers for electrical transmission system, IEEE press, Piscataway, 2002

[6] R. Narmatha Banu and D. Devraj, 'GA approach for optimal powerflow with FACTS devices" 4 th International IEEE Conference on intelligent systems,

\section{About Author's:}

Jitendra Bikaneria received his diploma in electrical engineering from board of technical education, Rajasthan, India in 1999 and his B.E. in electrical engineering from North Maharashtra University, Jalgaon, India, in 2003. Now he is pursuing his M.tech degree from Pacific University, Udaipur, India. $\mathrm{He}$ is a lecturer at government polytechnic college, Rajsamand, India. His field of interests includes photovoltaic modeling \& control, integral control, non linear system control \& optimization techniques such as genetic algorithm (GA) \& particle swarm optimization (PSO).

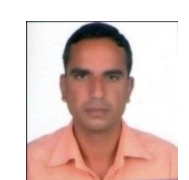

Surya Prakash Joshi received his B.E. in electrical engineering from university of Rajasthan, India in 2009. Now he is pursuing his M.tech degree from Rajasthan technical university, Kota, India. His interested field includes non conventional energy sources \& electrical machines. 